\title{
Influence of crude oil exposure on cardiac function and thermal tolerance of juvenile rainbow trout and European sea bass
}

\author{
Anttila Katja ${ }^{1,{ }^{*}}$, Mauduit Florian ${ }^{2}$, Le Floch Stéphane ${ }^{3}$, Claireaux Guy ${ }^{2}$, Nikinmaa Mikko ${ }^{1}$ \\ ${ }^{1}$ Department of BiologyUniversity of TurkuTurku,Finland \\ 2 Université de Bretagne Occidentale, LEMAR (UMR 6539)Centre Ifremer de BretagnePlouzané,France \\ ${ }^{3}$ CEDRE, Research DepartmentBrest Cedex 2,France \\ *Corresponding author : Katja Anttila, email address : katja.anttila@utu.fi
}

\begin{abstract}
:
Oil spills pose a threat to aquatic organisms. However, the physiological effects of crude oil on cardiac function and on thermal tolerance of juvenile fish are still poorly understood. Consequently, in this paper, we will present results of two separate experiments where we exposed juvenile rainbow trout and European sea bass to crude oil and made cardiac thermal tolerances and maximum heart rate (fHmax) measurements after 1 week (rainbow trout) and 6-month recovery (sea bass). In both species, the fHmax was lower in crude oil-exposed fish than in the control ones at temperatures below the optimum but this difference disappeared at higher temperatures. More importantly, the oil-exposed fish had significantly higher Arrhenius break point temperature for fHmax, which gave an estimate for optimum temperature, than the control fish in both species even though the exposure conditions and recovery times differed between species. The results indicated that exposure of juvenile fish to crude oil did not have a significant negative impact upon their cardiac performance in high temperatures and upper thermal tolerance increased when the fish were tested 1 week or 6 months after the exposure. Our findings suggest that the cardiac function and thermal tolerance of juvenile fish are relatively resistant to a crude oil exposure.
\end{abstract}

Keywords : Arrhenius break point temperature, Critical thermal maximum, CTMAX, Fish, Heart rate, Oil spill, $\mathrm{PAH}$ 


\section{Acknowledgements}

40

41 Authors would like to thank M. Hervy for providing us with the seabass, N. Le Bayon and

42 other members of the PFOM-ARN laboratory (Ifremer) for their technical assistance. We are

43 also thankful to Neste Oil for providing the crude oil for the experiments with rainbow trout.

44 The financial support by Kone Foundation and Turku Collegium for Science and Medicine

45 (KA), Academy of Finland (MN, project \# 258078), ITOPF and Total-Fluides through the

46 project FishHealth are also acknowledged. 


\section{Introduction}

Accidental oil spills and crude oil exposure represent a threat to aquatic environments

worldwide, affecting not only aquatic animals but also human activities (e.g. fisheries, aquaculture and tourism) (Endersen et al. 2003; Meski and Kaitaranta 2014). Previous studies have shown that fish embryos and larvae are particularly sensitive to crude oil and its components, especially polycyclic aromatic hydrocarbons (PAH). The heart is a particularly sensitive organ, with numerous reports associating crude oil exposure with malformations such as reduced cardiac looping and pericardial edema in developing fish (Thomaz et al. 2009; Incardona et al. 2009, 2012, 2014; Jung et al. 2013). Cardiac dysfunctions such as reduced ventricular contractility (Jung et al. 2013), increased occurrence of arrhythmias and variability of heart rate have also been reported in embryos (Incardona et al. 2009, 2012, 2014, Jung et al. 2013; Sørhus et al. 2016; Khursigara et al. 2017). Furthermore, it has been shown that a year after embryonic stages have been exposed to petroleum hydrocarbon, young fish still exhibit misshaped hearts and lower critical swimming velocities (UCRIT) than unexposed control fish (Hicken et al. 2011).

When comparing embryos to juveniles or adult fish, it seems that juveniles and adults might be less dramatically affected by exposure to petroleum hydrocarbons than younger life stages, although a large interspecific variability has been reported (e.g. Vosyliene et al. 2005; Davoodi and Claireaux 2007; Claireaux and Davoodi 2010; Milinkovitch et al. 2012; Claireaux et al. 2013). For example, common sole (Solea solea) and adult mahi-mahi (Coryphaena hippurus) showed reduced cardiac output when measured shortly after an exposure to crude oil (Davoodi and Claireaux 2007; Nelson et al. 2016). Johansen and Esbaugh (2017) observed that a $24 \mathrm{~h}$ acute exposure to $4.1 \mu \mathrm{g} \mathrm{L}^{-1} \Sigma \mathrm{PAH}$ reduced $\mathrm{U}_{\mathrm{CRIT}}$ and 
72 burst swimming capacity of adult red drum (Sciaenops ocellatus) while there was no change

73 in aerobic scope, cost of transport and in the capacity to repay oxygen debt following

74 exhaustive exercise. Brette et al. (2014) exposed isolated cardiomyocytes of juvenile bluefin

75 tuna (Thunnus orientalis) and yellowfin tuna (Thunnus albacares) to dilutions (20\%, $10 \%$

76 and 5\%) of high-energy water-soluble fraction (WAF) of oil samples collected from the

77 Deepwater Horizon spill. These authors observed impaired cardiomyocyte function during

78 the exposure, with reduced amplitude and tail current of the delayed rectifier potassium

79 current, resulting in prolonged action potential duration (Brette et al. 2014). It must be noted,

80 however, that the lack of effects has also been reported in the literature. For instance, aerobic

81 scope, basal and active metabolic rates as well as $U_{\text {CRIT }}$ were unchanged in juvenile golden

82 grey mullet (Liza aurata) 24h after oil exposure (Milinkovitch et al. 2012). Claireaux et al.

83 (2013) showed that 1 week after an exposure to crude oil or to chemically dispersed oil,

84 juvenile European seabass (Dicentrarchus labrax) displayed reduced hypoxia tolerance

85 (incipient lethal oxygen saturation) and thermal sensitivity (critical thermal maximum,

$\left.86 \mathrm{CT}_{\mathrm{MAX}}\right)$ compared to unexposed, control fish. These differences were, however, no longer

87 observed 4 weeks (Claireaux et al. 2013) or 10 months post-exposure (Mauduit et al. 2016).

89 Besides crude oil, fish are also exposed to other environmental changes in nature. One of

90 these is the ongoing climate change. Anthropogenic activities are changing the earth's

91 climate and water temperature has progressively increased around the world. This increase is

92 directly affecting the physiology of ectothermic fish and it is expected to have detrimental

93 effects if populations cannot migrate to new areas or increase their thermal tolerance via

94 phenotypic plasticity or adaptation through evolution by natural selection (Parmesan 2006;

95 BACC Author team 2008; Belkin 2009; Pörtner 2010; Marshall et al. 2014). The question is, 96 thus, to examine whether exposure to petroleum hydrocarbon compounds affects the capacity 
97 of fish to face warming events, such as heat waves for instance, the occurrence of which is

98 predicted to increase with climate change (e.g. Teng et al. 2016). In this paper, we

99 investigated the general nature of the consequences of crude oil-exposure on cardiac

100 performance and thermal tolerance of juvenile fish. In these experiments, juveniles of two 101 ecologically different fish species, the freshwater rainbow trout (Oncorhynchus mykiss) and 102 the seawater seabass were exposed to crude oil of different origin (trout: Russian export blend 103 medium crude oil; seabass: Arabian light crude oil), with (seabass) or without (trout)

104 treatment by dispersant. These species were chosen since they are important

105 fisheries/aquaculture species and are living/reared in areas where the threat from oil accident 106 is especially high (BACC Author team 2008; Marshall et al. 2014). Rainbow trout were 107 studied 1 week post exposure while seabass were examined 6 months post exposure. The 108 hypothesis was that oil exposure reduces the $\mathrm{CT}_{\mathrm{MAX}}$ and cardiac function of both species and 109 that the effects persist even after the fish have recovered in clean water.

\section{Materials and Methods}

This study contains two separate experiments that were done independently from each other, one in Finland with rainbow trout and one in France with seabass. In both experiments the endpoint measurements i.e. $\mathrm{CT}_{\mathrm{MAX}}$ and maximum heart rate were done similarly and the results were remarkably consistent. Therefore, these separate experiments are shown together as they give a uniform general view of how the crude oil exposure influences cardiac performance and thermal tolerance in juvenile fish. The measuring techniques (i.e. $\mathrm{CT}_{\mathrm{MAX}}$ and heart rate recordings) were used as screening tools and both techniques provided separate estimates of upper thermal tolerance of fish even though, in both cases, the rate of increase of temperature was higher than in natural situations. 
Since the experiments were done independently there were some differences between experiments that need to be noted. First, the origin of the crude oil used was different between experiments. Russian Export Blend medium crude oil was used in the rainbow trout study and Arabian light crude oil in the seabass study. Seabass were exposed to a ten times higher oil concentration than rainbow trout, since it had previously been shown that a lower concentration did not have a significant long-term effect on the thermal tolerance of seabass (Claireaux et al. 2013; Mauduit et al. 2016). Further, in seabass experiment chemical dispersant and weathering was used while in the rainbow trout study the crude oil was weathered. Water Total Petroleum Hydrocarbons (TPH) was analyzed in both experiments whereas PAHs were analyzed in the water in the trout experiment and in the liver in the seabass experiment.

\section{Experiment 1. Rainbow trout}

The experiments with rainbow trout (age 1+) were conducted at University of Turku, Finland during summer 2014. The experiments were approved by Finnish Animal Experiment Board (ESAVI/4068/04.10.07/2013). The rainbow trout were obtained from a nearby commercial fish farm (The College of Fisheries and Environment, Kirjala, Finland) and the fish were transported to University of Turku 4 weeks before experiments. Fish were maintained under natural photoperiod and temperature $\left(16^{\circ} \mathrm{C}\right)$ conditions in their acclimation tanks $(500 \mathrm{~L})$. Fish were fed daily with commercial pellets (Raisio Group, Raisio, Finland) and the feeding was ceased $24 \mathrm{~h}$ before any experiments/manipulations. The mean size of fish did not differ significantly between experimental groups and the weights and lengths were $4.6 \pm 0.5 \mathrm{~g}$ and

$1458.2 \pm 0.2 \mathrm{~cm}$ (fork length) for control rainbow trout, $4.4 \pm 0.3 \mathrm{~g}$ and $8.1 \pm 0.1 \mathrm{~cm}$ for oil-exposed 146 rainbow trout. 


\section{Exposures}

Russian Export Blend medium crude oil was acquired from Neste Oil (Raisio, Finland) and weathered at $22^{\circ} \mathrm{C}$ by bubbling air through the oil layer until approximately $10 \%$ of the oil mass was lost. Such a treatment of the oil simulated a $12 \mathrm{~h}$ aging of a slick released at sea (Nordvik 1995). Fish exposures were conducted according to Milinkovitch et al. (2011). Fish were allocated to two subgroups (oil-exposed and control, $n=60$ fish per group) and transferred from their acclimation tanks to identical, polyethylene tanks (185 L; 3 tanks per treatment) $48 \mathrm{~h}$ before exposures (biomass per tank $1.46 \mathrm{~g} \mathrm{~L}^{-1}$ ). The exposure tanks were equipped with air stones and custom-made mixing system, which allowed full homogenization of water column and kept oxygen level above $80 \%$ of air saturation throughout the exposures (see Milinkovitch et al. 2011 for further details about mixing system). Temperature of exposure tanks was kept at fish acclimation temperature $\left(16^{\circ} \mathrm{C}\right)$. The exposure was started by pouring $12.5 \mathrm{~g}$ of weathered crude oil to the surface of the tanks (i.e. the oil concentration was $0.07 \mathrm{~g} \mathrm{~L}^{-1}$ ) and lasted $48 \mathrm{~h}$. One liter water samples were taken from the middle of the water column of each tank, at the beginning and at the end of the exposure period. The TPH and PAH concentrations were analyzed from the water samples by Novalab Oy (Karkkila, Finland). Chemical analyses protocols are described in the supplementary 165 materials. The PAHs could not be measured from tissue samples in Novalab Oy. Following 166 exposure rainbow trout were briefly bathed in clean water containing $70 \mathrm{ppm}$ buffered MS167222 and the adipose fin cut to identify the fish later on. After bathing, fish were returned to 168 their initial acclimation tanks so that both control and exposed fish were under garden 169 conditions thereafter. Control fish followed the same protocol except that no chemicals were 170 added to their tank. No mortalities were observed during the exposure and the following 171 week. 
The $\mathrm{pH}$ of the water did not change during the exposure $(7.5 \pm 0.1)$ and nitrogen waste concentrations stayed below detection limits (nitrite $<0.25 \mathrm{mg} \mathrm{L}^{-1}$, nitrate $<10 \mathrm{mg} \mathrm{L}^{-1}$ and ammonium $\left.<0.5 \mathrm{mg} \mathrm{L}^{-1}\right)$. The oxygen concentration and water temperatures were $9.2 \pm 0.1 \mathrm{mg}$ $\mathrm{L}^{-1}$ and $16.3 \pm 0.05^{\circ} \mathrm{C}$, respectively.

$C T_{M A X}$ experiments

179 The first aim of our study was to examine whether a crude oil exposure, followed by a 180 significant recovery period in a clean environment, influenced the upper critical thermal 181 tolerance ( $\left.\mathrm{CT}_{\mathrm{MAX}}\right)$ of fish. This was verified by exposing control and oil-treated fish to an 182 acutely increasing temperature until the fish could no longer keep an upright position. The 184 time-limited (Sunday et al. 2015).

The $\mathrm{CT}_{\mathrm{MAX}}$ experiments with rainbow trout were conducted 7 days after the oil exposure according to Anttila et al. (2013b). Briefly, both control and exposed rainbow trout ( $n=15$ per group) were transferred to the experimental tank $\left(100 \mathrm{~L}, 16^{\circ} \mathrm{C}\right) 1 \mathrm{~h}$ before the experiment started. At the end of the acclimation period, the temperature of the water was increased at a constant rate of $0.3^{\circ} \mathrm{C} \min ^{-1}$ up to $24^{\circ} \mathrm{C}$ and by $0.1^{\circ} \mathrm{C} \min ^{-1}$ thereafter until the fish lost equilibrium. Water temperature was controlled with a circulating $2500 \mathrm{~W}$ heater (RC6, Lauda, Lauda-Königshofen, Germany). Water oxygenation and homogeneity were assured by bubbling air vigorously into the tanks and using aquarium pumps to circulate the water and keeping the oxygenation level above $80 \%$ of air saturation throughout the experiments. Once 195 a fish lost equilibrium, the water temperature was recorded and the fish was quickly removed 196 from the tank and placed in a recovery tank (all the fish had their own 10 L recovery tanks) at 
the acclimation temperature. After the experiment, the rainbow trout were euthanized with

200 ppm MS-222 buffered with sodium bicarbonate. The mass and length of the fish were recorded.

\section{Heart rate measurements}

202 The second aim of the study was to measure whether a crude oil exposure influenced the 203 maximum heart rate $\left(f_{H \max }\right)$ of the fish at different temperatures. With this technique we were 204 also able to estimate the upper thermal tolerance of cardiac function. The temperature where $205 f_{\text {Hmax }}$ stops increasing exponentially with increasing temperature (Arrhenius break point 206 temperature, $\mathrm{T}_{\mathrm{AB}}$ ) has been connected to optimum temperature of aerobic scope and growth 207 in several species (rainbow trout: Anttila et al. 2013a; coho salmon, Oncorhynchus kisutch: 208 Casselman et al. 2012; Atlantic salmon, Salmo salar: Anttila et al. 2014; sockeye salmon, $O$. 209 nerka: Chen et al. 2013; chinook salmon, O. tshawytscha: Muñoz et al. 2014; Arctic cod, 210 Boreogadus saida: Drost et al. 2014 and goldfish, Carassius auratus: Ferreira et al. 2014). 211 Thus, $\mathrm{T}_{\mathrm{AB}}$ was calculated and used as a proxy for the optimum temperature of fish $\left(\mathrm{T}_{\mathrm{OPT}}\right)$. We 212 also measured the temperature $\left(\mathrm{T}_{\mathrm{PEAK}}\right)$ where the highest heart rate $\left(f_{\text {Hpeak }}\right)$ was found and the 213 temperature where cardiac arrhythmias were observed $\left(\mathrm{T}_{\mathrm{ARR}}\right)$. These temperature values were 214 indicative the upper thermal limit for cardiac function (Casselman et al. 2012; Anttila et al. 215 2013a).

$217 f_{\text {Hmax }}$ of rainbow trout was measured a week after the exposure $(n=12$ per group, different 218 fish from those in $\mathrm{CT}_{\mathrm{MAX}}$ measurements). The measurements were done according to 219 Casselman et al. (2012) with slight adjustments in drug concentrations. Briefly, the fish were 220 anesthetized in buffered 80 ppm MS-222, weighted and placed in the experimental setup. The 221 set-up consisted of 4 chambers made of a PVC-pipe with sealed ends and top removed so that 
fish were completely submerged. A water flow to these chambers was achieved via a chilling/heating unit (RC6, Lauda, Lauda-Königshofen, Germany). Note that a portion of that water flow was diverted, via pipe-mouthpieces, through fish mouth and gills. This water contained a maintenance dose of anesthetics (70 ppm of buffered MS-222). To detect fish electrocardiogram (ECG), two silver electrodes were placed on the bottom of each chambers underneath the fish. The signal from these electrodes was amplified and filtered using a Grass P122 AC/DC Strain Gage Amplifier (Grass Technologies, Warwick, U.S.A.). ECG recording and analysis were performed with BIOPAC data acquisition unit (MP100) and Acknowledge software (ver. 3.9.1.).

232 Following their transfer into the experimental chambers, fish were equilibrated at the initial 233 temperature $\left(12^{\circ} \mathrm{C}\right)$ for $1 \mathrm{~h}$, after which they were given an intraperitoneal injection of 234 atropine sulphate (1.8 $\mathrm{mg} \mathrm{kg}^{-1}$, Sigma-Aldrich Chemie Gmbh, Munich, Germany) to 235 completely block the vagal tone. Fifteen minutes later fish were given an isoproterenol 236 injection (4 $\mathrm{g} \mathrm{kg}^{-1}$, Sigma-Aldrich Chemie Gmbh, Munich, Germany) to maximally 237 stimulate cardiac $\beta_{1}$-adrenoceptors. Both drugs were dissolved in saline $(0.9 \% \mathrm{NaCl})$. These 238 drug concentrations had been tested in preliminary experiments to ensure that maximum heart 239 rate was recorded. Once heart rate had stabilized (15 min after the isoproterenol injection), 240 water temperature was increased in $1^{\circ} \mathrm{C}$ increments at a rate of $10^{\circ} \mathrm{C} \mathrm{h}^{-1}$. After every 241 temperature increment, heart rate was allowed to stabilize before recording a value. Warming 242 continued until cardiac arrhythmias developed, after which fish were rapidly removed from 243 the apparatus, euthanized by cranial percussion and their weight and length measured.

245 For each individual fish temperatures corresponding to $\mathrm{T}_{\mathrm{ARR}}$ and $\mathrm{T}_{\mathrm{PEAKT}}$ were recorded and 246 the $\mathrm{T}_{\mathrm{AB}}$ was calculated with Arrhenius plots according to Yeager and Ultsch (1989). 


\section{Experiment 2. Seabass}

249 The seabass (age $1+; 11.3 \pm 1.1 \mathrm{~cm} ; 17.7 \pm 5.0 \mathrm{~g}$ ) were obtained from Aquastream Lorient, 250 France and transferred to a 2000-L rearing tank at Unité de Physiologie Fonctionnelle des 251 Organismes Marins, Ifremer, France. They were maintained under natural photoperiod and 252 temperature conditions $\left(10^{\circ} \mathrm{C}\right.$ at the time of arrival) and fed daily with commercial pellets (Le 253 Gouessant, Saint-Martin de Valgalgues, France). Fish were acclimated 8 weeks to the 254 laboratory conditions before experiments began and feeding was ceased $24 \mathrm{~h}$ before any 255 experiments/manipulations. Two weeks before experiments started, seabass were 256 anaesthetized (MS-222; $100 \mathrm{mg} \mathrm{L}^{-1}$, Sigma-Aldrich Chimie Gmbh, Munich, Germany) and 257 individually implanted subcutaneously with an identification tag (RFID; Biolog-id, Bernay, 258 France). All the experiments were approved by Ministère Délégué à l'Enseignement 259 Supérieur et à la Recherche.

261 Exposures

262 The exposures were conducted as in experiment 1, apart from a different crude oil (Arabian 263 light crude oil) and concentration $\left(0.8 \mathrm{~g} \mathrm{~L}^{-1}\right)$. A higher concentration was used because it has 264 been previously shown that a lower concentration $\left(0.07 \mathrm{~g} \mathrm{~L}^{-1}\right)$ did not influence the thermal 265 tolerance of seabass (Claireaux et al. 2013; Mauduit et al. 2016). Furthermore, in the 266 experiment with seabass, crude oil was treated with dispersant (Finasol OSR 52, $0.017 \mathrm{~g} \mathrm{~L}^{-1}$ ) 267 while in the experiment with rainbow trout weathered oil was only mechanically dispersed in 268 water. In seabass experiment $250 \mathrm{~g}$ of crude oil and $10 \mathrm{~g}$ of dispersant was mixed vigorously in 269 three separate bottles. The oil-dispersant mixture was directly poured in the three $300 \mathrm{~L}$ 270 experimental tanks and then bubbled with air overnight to mimic a 12-h aging of an oil slick 271 at sea (Nordvik 1995). The number of exposed seabass per treatment was 180. Exposure 
started when sixty fish were transferred for $48 \mathrm{~h}$ into triplicate exposure tanks that contained

\section{$C T_{M A X}$ experiments}

Experiments were conducted 4 weeks post oil-exposure. The $\mathrm{CT}_{\mathrm{MAx}}$ protocol $(n=20$ per group) differed slightly from the protocol for rainbow trout in that the thermal challenge test was conducted directly in the fish rearing tank. Moreover, temperature was increased from acclimation temperature to $27^{\circ} \mathrm{C}$ in 2.5 hours and thereafter the heating rate was lowered to $0.5^{\circ} \mathrm{C} \mathrm{h}^{-1}$ until the last fish lost its equilibrium and was removed from the tank (Claireaux et al. 2013). The water temperature was controlled with JULABO F10, $2500 \mathrm{~W}$ heater (Seelbach, Germany). Each time a fish lost its ability to maintain an upright position, the water temperature was recorded, the fish PIT tag number was read and it was transferred to a recovery tank for $2 \mathrm{~h}$ before being returned to its original rearing tank. The percentage of mortality after the $\mathrm{CT}_{\mathrm{MAX}}$ experiment was below $1 \%$. Fish were then reared under natural photoperiod and temperature conditions until heart rate measurements (6 months later). There were no differences in mortality between groups. 


\section{Heart rate measurements}

298 Maximum heart rate of seabass ( $n=18$ per group, the same fish as in $\mathrm{CT}_{\mathrm{MAX}}$ measurements)

299 was measured 6 months after oil exposure (water temperature at that time was $17^{\circ} \mathrm{C}$ ). At the

300 time of heart rate measurements, the mean size of fish did not differ significantly between groups $(66.4 \pm 4.1 \mathrm{~g}$ and $17.2 \pm 0.3 \mathrm{~cm}$ for control seabass and $71 \pm 3.7 \mathrm{~g}$ and $17.5 \pm 0.3 \mathrm{~cm}$ for oil-exposed seabass, respectively). The experimental protocol was exactly the same as with rainbow trout except that anesthesia solution did not contain bicarbonate because of the buffering capacity of seawater. Salinity level of the water was 32-33 ppt. The water temperature was controlled with a recirculating chiller/heater (F10, JULABO, Seelbach, Germany) and the ECG was recorded and analyzed with BioPac MP36R (BIOPAC Systems Inc, Essen, Germany) which had an in-built amplification system. The starting temperature of the measurements for seabass was $17^{\circ} \mathrm{C}$. The concentration of atropine sulphate was $3 \mathrm{mg} \mathrm{kg}$

${ }^{1}$ (Sigma-Aldrich Chemie Gmbh, Munich, Germany) and the concentration of isoproterenol was $3.2 \mu \mathrm{g} \mathrm{kg}^{-1}$ (Sigma-Aldrich Chemie Gmbh, Munich, Germany).

\section{Statistical analyses of both experiments}

313 Data normality and homogeneity were tested with Kolmogorov-Smirnov and Levene tests, 314 respectively. Two-way repeated measures ANOVA was used to calculate the differences in $315 f_{\text {Hmax }}$ values between oil-exposed and control fish during warming (temperature and treatment 316 as factors) and was followed by Holm-Sidak post hoc test. Both species were tested 317 separately because of differences in starting temperatures and treatments. Two-way repeated 318 measures ANOVAs were also used to analyze 1) the differences in $f_{\text {Hpeak }}$ and scope for heart 319 rate (difference between lowest $f_{\text {Hmax }}$ and $f_{\text {Hpeak }}$ ) between exposed and control animals and 2) 320 the differences in $\mathrm{T}_{\mathrm{AB}}, \mathrm{T}_{\mathrm{PEAK}}, \mathrm{T}_{\mathrm{ARR}}, \mathrm{CT}_{\mathrm{MAX}}$ between exposed and control animals (exposure 321 and measurement as factors). However, since the individuals for $\mathrm{CT}_{\mathrm{MAX}}$ experiment were 
different from individuals used in heart rate experiment for rainbow trout, the differences in

$\mathrm{CT}_{\mathrm{MAX}}$ between exposed and control rainbow trout were analyzed with t-test. All the statistical analyses were performed with SigmaPlot 13 (Systat Software Inc., San Jose, CA, USA). Statistical significance for comparisons of mean values was set at $\alpha=0.05$. The values are presented as means \pm SEM.

\section{Results}

\section{Experiment 1. Rainbow trout}

331 Rainbow trout were exposed to $0.07 \mathrm{~g} \mathrm{~L}^{-1}$ of weathered Russian export blend medium crude 332 oil. The mean $\sum$ hydrocarbons in water samples from the three exposure tanks at the end of 333 the exposure period was $3.8 \pm 1.1 \mathrm{mg} \mathrm{L}^{-1}$ while the sum of $16 \mathrm{US}-\mathrm{EPA}$ PAHs was $4.5 \pm 0.14 \mu \mathrm{g}$

$334 \mathrm{~L}^{-1}$. However, it needs to be noted that only naphthalene, acenaphtalene, fluorene and 335 phenantrene concentrations were above detection limits. The list of assayed PAH compounds 336 is shown in a Supplementary Table. There were no mortalities after exposures.

Heart rate

Exposure to crude oil reduced the heart rate at temperatures below and near optimum temperature $\left(12-18^{\circ} \mathrm{C}\right.$, optimum around $17^{\circ} \mathrm{C}$, Anttila et al. 2013a) $\left(F_{1,6}=6.3, P=0.013\right.$, Fig. 1a) while there were no differences between oil-exposed and control fish at temperatures $>18^{\circ} \mathrm{C}$. Oil exposure did not affect the highest $f_{\text {Hmax }}$ recorded $\left(f_{\text {Hpeak }}\right)(108 \pm 5.1 \mathrm{bpm}$ and 116 $\pm 6.7 \mathrm{bpm}$ for control and oil-exposed rainbow trout, respectively; $P=0.29$ ). The difference between the lowest recorded $f_{\mathrm{Hmax}}$ and the highest recorded $f_{\mathrm{Hmax}}$ (scope for heart rate) were $50.2 \pm 4.1$ and $64.5 \pm 6.5 \mathrm{bpm}$ in control and oil-exposed rainbow trout, respectively, and were not statistically different from each other $(P=0.088)$. 


\section{Indices of upper thermal tolerance}

Oil exposure had a significant influence on rainbow trout thermal tolerance (Fig. 2a). One week post exposure, $\mathrm{T}_{\mathrm{AB}}$ was significantly higher in oil-exposed $\left(16.3 \pm 0.4^{\circ} \mathrm{C}\right)$ than in control $\left(15.1 \pm 0.4^{\circ} \mathrm{C}\right)$ fish $(P=0.036$, Fig. 1a, 2a). Similarly, all the indices of upper thermal tolerances (i.e. $\mathrm{T}_{\mathrm{PEAK}}, \mathrm{T}_{\mathrm{ARR}}$ and $\mathrm{CT}_{\mathrm{MAX}}$ ) were higher in oil-exposed than in control rainbow trout: the differences between oil-exposed and control fish were $1.8^{\circ} \mathrm{C}, 2.3^{\circ} \mathrm{C}$ and $0.8^{\circ} \mathrm{C}$, for $\mathrm{T}_{\mathrm{PEAK}}$, $\mathrm{T}_{\mathrm{ARR}}$ and $\mathrm{CT}_{\mathrm{MAX}}$, respectively (Fig. 2a) (T

$\mathrm{CT}_{\mathrm{MAX}}, \mathrm{T}_{\mathrm{ARR}}, \mathrm{T}_{\mathrm{PEAK}}$ and $\mathrm{T}_{\mathrm{AB}}$ differed significantly from each other $(P<0.001)$.

\section{Experiment 2. Seabass}

358 The $\sum$ hydrocarbons experienced by seabass at the end of the exposure to $0.8 \mathrm{~g} \mathrm{~L}^{-1}$ of 359 weathered Arabian light crude oil mixed with $0.017 \mathrm{~g} \mathrm{~L}^{-1}$ of dispersant (Finasol OSR 52) was $360141 \pm 7.8 \mathrm{mg} \mathrm{L}^{-1}$. Twenty four hours post-exposure, the sum of 16 US-EPA PAHs and 5 361 supplementary PAHs (benzo[b]thiophene, biphenyl, dibenzothiophene, benzo[e]pyrene and 362 perylene) in seabass liver $(n=9)$ was $34299 \pm 8926 \mathrm{ng} \mathrm{g}^{-1}$. The concentrations of PAHs are 363 detailed in Supplementary table.

\section{Heart rate}

366 The exposure to crude oil caused similar effects in seabass as observed in rainbow trout

367 although experimental designs and post-exposure recovery times were different. For example, 368 in seabass, as in rainbow trout, the oil-exposed fish had lower $f_{\text {Hmax }}$ values $\left(F_{1,5}=4.8, P=0.03\right)$

369 than the control fish when measured below the optimum temperature $\left(17-22^{\circ} \mathrm{C}\right.$, optimum 370 around $22-24^{\circ} \mathrm{C}$, Claireaux and Lagardère 1999), (Fig. 1b). However, there were no 371 differences between oil-exposed and control seabass at temperature $>24^{\circ} \mathrm{C}$. As in rainbow 
trout the oil exposure did not influence the $f_{\text {Hpeak }}$ values $(P=0.91)$. The values for $f_{\text {Hpeak }}$ were $125 \pm 6.7 \mathrm{bpm}$ and $126 \pm 4.9 \mathrm{bpm}$ for control and oil-exposed seabass, respectively. The scopes for $f_{\mathrm{Hmax}}$ were $34.0 \pm 5.0$ and $35.7 \pm 5.8$ for control and oil-exposed seabass, respectively, and the groups did not differ from each other $(P=0.83)$.

\section{Indices of upper thermal tolerance}

378 Again, as in rainbow trout, the oil-exposed seabass had higher $\mathrm{T}_{\mathrm{AB}}\left(1.0^{\circ} \mathrm{C}\right.$ difference $)$ 379 compared to control seabass $(P=0.05)$. The $\mathrm{T}_{\mathrm{AB}}$ values were $19.3 \pm 0.3^{\circ} \mathrm{C}$ and $20.3 \pm 0.3^{\circ} \mathrm{C}$ for 380 control and oil-exposed seabass, respectively (Fig. 1d, 2b). Furthermore, the TPEAK was 381 higher $\left(P=0.03\right.$, difference $1.3^{\circ} \mathrm{C}$, Fig. $\left.2 \mathrm{~b}\right)$ in oil-exposed seabass than in the control. The

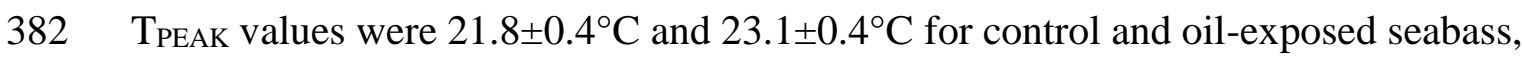
383 respectively. However, in seabass the $\mathrm{T}_{\mathrm{ARR}}$ and $\mathrm{CT}_{\mathrm{MAX}}$ did not differ statistically between oil384 exposed and control fish after a 6-month recovery (T $\mathrm{T}_{\mathrm{ARR}}: P=0.62$; $\mathrm{CT}_{\mathrm{MAX}}: P=0.94$, Fig. 2 b).

\section{Discussion}

Recent studies have demonstrated that embryonic fish exposed to hydrocarbon compounds can display various cardiac malformations and functional disorders (e.g. Thomaz et al. 2009; Incardona et al. 2009, 2012, 2014; Jung et al. 2013; Sørhus et al. 2016; Khursigara et al. 2017). However, there is very limited literature available about the influence of petroleum hydrocarbon exposure on later life stages. Moreover, when available, reports about disturbed homeostasis or functional disorders generally concern a very short period post exposure, preventing attempts to draw the distinction between normal regulatory processes, a stress response or a true, potentially long-lasting, functional disorders. The aim of the current study was, therefore, to measure, in experiments involving two different fish species, how exposure 
to crude oil, followed by a significant recovery period in a clean environment, influenced the

upper critical thermal tolerance and cardiac function of juvenile fish. We found that a week

(trout) to months (seabass) post exposure, crude oil-exposed fish displayed higher (trout) or

unchanged (seabass) upper critical thermal tolerance than control, unexposed fish. We also

found that crude oil did not have a significant chronic residual influence on the cardiac

performance of our juvenile fish at high temperatures. In contrast to what was expected, our estimate of optimal temperature for cardiac function even increased after exposure in both species.

The upper critical temperature ( $\left.\mathrm{CT}_{\mathrm{MAX}}\right)$ corresponds to temperature at which a fish exposed to a progressive and controlled increase in water temperature is no longer able to maintain an upright position. When the $\mathrm{CT}_{\text {MAX }}$ is reached survival is time-limited and, thus, $\mathrm{CT}_{\text {MAX }}$ is used as a proxy for upper critical thermal tolerance of fish (Sunday et al. 2015). In the current study, we observed that the oil-exposed rainbow trout had a significantly higher $\mathrm{CT}_{\mathrm{MAX}}$ than control fish. In seabass, on the other hand, no difference in $\mathrm{CT}_{\mathrm{MAX}}$ was observed between control and oil-exposed fish. These values $\left(29.0 \pm 0.2^{\circ} \mathrm{C}\right.$ for rainbow trout acclimated at $16^{\circ} \mathrm{C}$ and $31.3 \pm 0.3^{\circ} \mathrm{C}$ for seabass acclimated to $17^{\circ} \mathrm{C}$ ) were similar to those reported earlier (29.4 ${ }^{\circ} \mathrm{C}$ and $28-35^{\circ} \mathrm{C}$, Beitinger et al. 2000; Claireaux et al. 2013). It has previously been found in juvenile seabass that exposure to crude oil $\left(0.07 \mathrm{~g} \mathrm{~L}^{-1}\right)$ did not affect their upper critical thermal tolerance $\left(\mathrm{CT}_{\mathrm{MAX}}\right)$ when the measurements were done ten months after exposure (Mauduit et al. 2016). The present study, using 12.5 times higher oil concentration, confirms that exposure to petroleum hydrocarbons has no significant, long-term effect on upper critical thermal tolerance in this species. Since we did not measure $\mathrm{CT}_{\mathrm{MAX}}$ immediately 420 after oil exposure it is not certain whether this lack of effect results from a recovery process 421 or that oil-exposure has simply no effect on thermal tolerance in juvenile fish. However, 
Claireaux et al. (2013) have shown that shortly after oil exposure juvenile seabass do display a reduction in $\mathrm{CT}_{\mathrm{MAX}}$. This therefore suggests that juvenile fish have the capacity to recover from the initial impact of oil exposure on their upper critical thermal tolerance.

Optimal temperatures $\left(\mathrm{T}_{\mathrm{OPT}}\right)$ of rainbow trout and seabass are $16.5-17^{\circ} \mathrm{C}$ and $22-24^{\circ} \mathrm{C}$, respectively (Jobling 1981; Claireaux and Lagardère, 1999). In both species we observed that at suboptimal temperatures, maximum heart rate $\left(f_{\mathrm{Hmax}}\right)$ of oil-exposed individuals was lower than in control specimens. Previously, Milinkovitch et al. (2013) have found in juvenile golden grey mullet exposed to crude oil $\left(0.07 \mathrm{~g} \mathrm{~L}^{-1}, \sum \mathrm{PAH} 3.3-60.1 \mu \mathrm{g} \mathrm{L}^{-1}\right)$ that the capacity of ventricular muscle strips to generate force at suboptimal temperature $\left(14.5^{\circ} \mathrm{C}\right)$ and high stimulation frequency $(1.2 \mathrm{~Hz})$ was not affected when measured directly after exposure. Furthermore, these authors reported that oil exposure did not significantly affect the forcefrequency relationship established in control, unexposed fish. Similarly, Nelson et al. (2016) found that a $24 \mathrm{~h}$ exposure to PAHs $\left(9.6 \mu \mathrm{g} \mathrm{L}^{-1}\right)$ did not influence the routine heart rate of adult mahi-mahi when measured directly after exposure. However, a significant decrease in routine cardiac output was reported by these authors, probably resulting from a decreased stroke volume. Claireaux and Davoodi (2010) found that juvenile common sole had reduced cardiac output, as well as impaired cardio-respiratory responses to an acute warming, $24 \mathrm{~h}$ after exposure to crude oil ( $\sum$ PAH $39 \mathrm{ng} \mathrm{L}^{-1}$ of water and 15-71 $\mathrm{ng} \mathrm{g}^{-1}$ dry liver tissues). These authors found that $24 \mathrm{~h}$ post-exposure there was no statistically significant difference in routine heart rates between oil-exposed and control sole at temperatures between $15-20^{\circ} \mathrm{C}$ (optimal temperature in sole is $19^{\circ} \mathrm{C}$; Lefrançois and Claireaux 2003). However, a difference progressively appeared when temperature increased above $20^{\circ} \mathrm{C}$ with the cardiac output of the oil-exposed common soles gradually losing its capacity to match the temperature driven increase in metabolic oxygen demand (Claireaux and Davoodi 2010). There are no other 
447 studies about the effect of crude oil or PAHs on heart rate in non-embryonic fish. However,

work on embryonic fish indicates that exposure conditions affect the cardiac response to oil compounds. For example, developing zebrafish (Danio rerio) exposed to oiled gravel effluent displayed reduced routine heart rate, while exposure to water-accommodated fractions containing dispersed oil microdroplets had no effect (Jung et al. 2013). In Pacific herring (Clupea pallasi), oiled-gravel exposure increased the variability of routine heart rate and generally reduced it (Incardona et al. 2009). A similar response was observed in herring embryos exposed to bunker fuel after Cosco Busan collision in San Francisco Bay (Incardona et al. 2012), as well as in haddock (Melanogrammus aeglefinus) embryos exposed 0.7-7 $\mu \mathrm{g}$ $\mathrm{L}^{-1} \sum \mathrm{PAH}$ (Sørhus et al. 2016) and in rainbow trout larvae exposed to $1.6 \mathrm{~g} \mathrm{~L}^{-1}$ of crude oil (Vosyliene et al. 2005). An exposure to $\sum \mathrm{PAH} \sim 2-5 \mu \mathrm{g} \mathrm{L}^{-1}$ (which is similar to the PAH concentration in our experiment with rainbow trout) reduced routine heart rate in embryos of bluefin and yellowfin tuna (Incardona et al. 2014). In larval red drum (Sciaenops ocellatus) the exposure to crude oil (2.6 $\left.\mu \mathrm{g} \mathrm{L}^{-1} \Sigma \mathrm{PAH}\right)$ reduced the routine stroke volume but did not affect heart rate (Khursigara et al. 2016). In the current study, the reduction of $f_{\mathrm{Hmax}}$ at suboptimal temperatures in the oil-exposed fish was rather small ( $\sim \mathrm{bpm})$. Thus, it seems that the juvenile fish might be more resistant against oil-exposure than earlier life stages. In embryonic and larval fish significant reductions in heart rate and arrhythmias are seen already after nominal exposure to PAHs (e.g. Thomaz et al. 2009; Incardona et al. 2009, 2012, 2014; Jung et al. 2013; Sørhus et al. 2016; Khursigara et al. 2017). Furthermore, exposure in embryonic stages may have extremely long lasting effects e.g. on swimming capacity (Hicken et al. 2011; Mager et al. 2014) which could have consequences on the ecology of whole species. 
In the current study despite the fact that $f_{\mathrm{Hmax}}$ was lower in exposed fish than in control fish at temperatures below the optimal temperature ( $\left.\mathrm{T}_{\mathrm{OPT}}\right)$ of the species considered, this difference disappeared at temperature above TOPT. As a result, the highest $f_{\text {Hmax }}$ values were similar in exposed and control fish. Thermal tolerance of cardiac function i.e., TPEAK (temperature where highest $f_{\text {Hmax }}$ was observed) and $\mathrm{T}_{\mathrm{ARR}}$ (temperature where arrhythmias were observed) were also higher in exposed rainbow trout than in control trout. In seabass, $\mathrm{T}_{\text {PEAK }}$ was also higher in exposed than in control seabass. Furthermore, in both species Arrhenius break point temperature $\left(\mathrm{T}_{\mathrm{AB}}\right)$, which is indicative of the species' optimal temperature (e.g. Casselman et al. 2012; Anttila et al. 2013a; Ferreira et al. 2014), was higher in oil-exposed animals than in control ones. In general, these findings show that oil-exposure does not have significant negative impact either on cardiac function at high temperatures or the thermal tolerance of cardiac function. These are important findings, as in several species at high temperatures the maximum cardiac function is critical for fish survival through preserving aerobic capacity (Steinhausen et al. 2008; Farrell 2009; Eliason et al. 2013). A 4-month field experiment recently illustrated the ecological significance of these results as the survival and growth of juvenile oil-exposed seabass $\left(0.07 \mathrm{~g} \mathrm{~L}^{-1}\right)$ was shown to be similar to that of control fish although they were exposed to naturally high summer temperatures (Mauduit et al. 2016).

Taken together, our heart rate results indicate that oil exposure does not have significant lasting negative impact on the $f_{\text {Hmax }}$ on juvenile fish when fish are tested after sufficient recovery time following exposure. Again, we cannot be sure if this is because of the recovery capacity or because used crude-oil concentrations do not have impact on maximum heart rate in the first place. Previously, Johansen and Esbaugh (2017) have shown in adult red drum (Sciaenops ocellatus) that acute oil exposure $\left(12.1 \mu \mathrm{gL}^{-1} \Sigma \mathrm{PAH} 50\right)$ reduced the swimming capacity as well as aerobic scope and that these effects were still seen 6 weeks post exposure. We can therefore assume that oil-exposure in the current study did not have significant effect 
on $f_{\text {Hmax }}$ in the first place. However, it cannot be ruled out that other aspects of cardiac function, like stroke volume, would have been influenced as seen in mahi-mahi (Nelson et al. 2016).

Our values for heart rate and upper thermal tolerance lie within the range of published values from these animals. Rainbow trout swimming at maximum sustainable velocity at $15^{\circ} \mathrm{C}$ has a heart rate of $96 \mathrm{bpm}$ after vagotomy (Priede 1974). This value compares nicely with the values of $80 \mathrm{bpm}$ observed in the present study (see also Mercier et al. 2000). The maximum heart rate of exercising seabass has been measured at around $90 \mathrm{bpm}$ at $20^{\circ} \mathrm{C}$ (Chatelier et al. 2005) which agrees relatively well with the current finding of $90 \mathrm{bpm}$ at $17^{\circ} \mathrm{C}$. The $\mathrm{T}_{\mathrm{AB}}$ values $\left(15.1 \pm 0.4^{\circ} \mathrm{C}\right.$ and $19.3 \pm 0.3^{\circ} \mathrm{C}$ for rainbow trout and seabass, respectively) are somewhat lower, but near the optimum growth temperatures of these species $\left(16.5-17^{\circ} \mathrm{C}\right.$ and 22-24 ${ }^{\circ} \mathrm{C}$, Jobling 1981; Claireaux and Lagardère 1999).

The two experiments that are reported here were conducted separately and differences in the experimental conditions and design must be considered, i.e., PAH composition of the oil tested, duration of the post-exposure recovery, concentration of crude oil tested, usage of dispersant and availability of tissue PAH concentrations.

Crude oil used in the seabass and trout experiments was of different origin and this was particularly reflected in their composition of PAHs, the most potent oil compounds from the cardiac standpoint. In embryonic fish it has been shown that PAHs are particularly detrimental to the cardiac function although reported effects are compound-specific (see review by Incardona and Scholz 2016). For instance naphthalene, chrysene, anthracene and benzo[k]fluoranthene, abundant PAHs in both tested oils, are known for having only small 
effects on the physiology (conduction properties) and anatomy/pathology (pericardial edema)

of the heart (Incardona et al. 2004; 2011). On the other hand, dibenzothiophene and phenanthrene have been shown to cause pericardial edema and to reduce heart rate by blocking atrioventricular conduction in a concentration-dependent manner (Incardona et al. 2004). Furthermore, benzo[e]pyrene and benzo[a]pyrene have also been shown to induce pericardial edema (Incardona et al. 2011). In the current experiments phenantherene was present in the water and fish tissues and dibenzothiophene was even the most abundant PAH in the seabass experiment. Thus, from this stand point, both oils contained PAH compounds that should have had influence on cardiac function.

Another difference between the two experiments is the duration of the post-exposure recovery period. The rainbow trout measurements were done one week after the exposure while seabass were measured 6 months post-exposure. The short-term effects of oil exposure upon the cardiac function are well documented (e.g. Incardona et al. 2009, 2012, 2014; Claireaux and Davoodi 2010; Jung et al. 2013; Milinkovitch et al. 2013; Brette et al. 2014; Nelson et al. 2016; Sørhus et al. 2016; Khursigara et al. 2017). A review of the literature shows, however, that published studies of the toxicological impacts of oil exposure on fish predominantly investigated acute exposure, short exposure duration and immediate assessment, mostly at low biological organization levels. While these studies contribute to increase our mechanistic understanding of contamination and decontamination processes (e.g. Ramachandran et al. 2004; Milinkovitch et al. 2013; Danion et al. 2014; Dussauze et al. 2014; Sadauskas-Henrique et al. 2016; Sandrini-Neto et al. 2016; Sanni et al. 2016), they are of limited help when addressing issues such as, for instance, impact on the resilience, health, production and recruitment of the affected populations (Forbes et al. 2006). From this perspective, the present experiments are remarkable as, although providing little additional 
546 information about the well documented patterns of PAH bioaccumulation and metabolization

547 in fish (Claireaux and Davoodi 2010; Milinkovitch et al. 2013; Nelson et al. 2016), they

548 provide evidence in favor of the absence of chronic latent effects of oil exposure on fish

549 thermal tolerance and cardiac performance. These results substantiate the recovery process reported by Claireaux et al. (2013) and Mauduit et al. (2016) regarding swimming capacity, tolerance to heat and to hypoxia. Interestingly, although the two sets of experiments involved two different fish species with quite different exposures and at two different times postexposure, very similar response patterns were observed. This is an important result, because it shows that cardiac recovery could be a relatively general phenomenon in juvenile fish. However, in order to evaluate the recovery process more thoroughly, more time points should be examined in future.

558 One other difference between the two studies was that we didn't use dispersant in the trout 559 study and that tissue PAH concentrations were not measured in that species. Nevertheless, 560 nominal concentrations tested in present studies are representative of the concentrations 561 measured following an accidental spill (Boehm and Fiest 1982; Milinkovitch et al. 2011), 562 which have been shown to result in detrimental effects on cardiac function when measured 563 within days-weeks post-exposure (e.g. Claireaux and Davoodi 2010; Incardona et al. 2014; 564 Sørhus et al. 2016; Khursigara et al. 2017).

566 In conclusion, exposure to crude oil did not have a significant impact on maximum heart rate 567 and cardiac function of juvenile fish at temperatures above their optimum when the 568 measurements were done 1 week (trout) to 6 months (seabass) after the exposure. We 569 observed that exposure may even improve the upper thermal tolerance of fish. The reason for 570 this unexpected result is unknown, thus, future studies should focus on this issue. Our 
571 findings also suggest that recovery processes exist that can reverse the functional

1

2 3 4

5573 important finding for the fisheries as both of these species are important human food species 6

9 10 11 12 13 14 15 16 17 18 19 20 21 22 23 24 25 26 27 28 29 30 31
572 impairments observed shortly following direct exposure in previous studies. This is also an

574 and are living/reared at areas where the threat for both oil accidents and warming surface 


\section{Figure legends}

578 Fig. 1 The cardiac responses to increasing temperature in control and oil-exposed fish after

579 one-week (rainbow trout) and six-month (seabass) recovery. The effect of increasing 580 temperature on the maximum heart rate $\left(f_{\mathrm{Hmax}}\right)$ of $\mathbf{a}$ juvenile rainbow trout and $\mathbf{b}$ European 581 seabass. The grey area indicates the temperature window where there are significant 582 differences between control and oil-exposed fish. The dotted lines indicate temperatures 583 where some of the fish already had arrhythmias. The Arrhenius plots of $f_{\text {Hmax }}$ responses to 584 increasing temperature for rainbow trout are given in $\mathbf{c}$ and for seabass in $\mathbf{d}$. The vertical lines 585 (dotted line for oil-exposed fish, solid line for control fish) indicate an Arrhenius break point 586 temperature $\left(\mathrm{T}_{\mathrm{AB}}\right) \cdot n=12$ for rainbow trout and $n=18$ for seabass

588 Fig. 2 The temperature tolerance values of control and oil-exposed fish. Arrhenius break 589 point temperature $\left(\mathrm{T}_{\mathrm{AB}}\right)$, temperature for peak maximum heart rate $\left(\mathrm{T}_{\mathrm{PEAK}}\right)$, temperature 590 where cardiac arrhythmias are observed $\left(\mathrm{T}_{\mathrm{ARR}}\right)$ and critical upper temperature tolerance 591 ( $\left.\mathrm{CT}_{\mathrm{MAX}}\right)$ of a rainbow trout and $\mathbf{b}$ European seabass. * indicates statistically significant 592 differences between oil-exposed and control fish. $n=12$ for rainbow trout (except for CTMAX measurements $n=15$ ) and $n=18$ for seabass (except for $\mathrm{CT}_{\mathrm{MAX}}$ measurements $n=20$ ) 


\section{Compliance with ethical standards}

\section{Conflict of Interest}

597 The authors declare that they have no conflict of interest.

\section{References}

601 Anttila K, Casselman MT, Schulte PM, Farrell AP (2013a) Optimum temperature in juvenile 602 salmonids: connecting subcellular indicators to tissue function and whole-organism thermal 603 optimum. Physiol Biochem Zool 86:245-256.

605 Anttila K, Dhillon RS, Boulding EG, Farrell AP, Glebe BD, Elliott JA, Wolters WR, Schulte 606 PM (2013b) Variation in temperature tolerance among families of Atlantic salmon (Salmo 607 salar) is associated with hypoxia tolerance, ventricle size and myoglobin level. J Exp Biol 608 216:1183-1190.

610 Anttila K, Couturier CS, Øverli Ø, Johnsen A, Marthinsen G, Nilsson GE, Farrell AP (2014)

611 Atlantic salmon show capability for cardiac acclimation to warm temperatures. Nat Commun $6125: 4252$.

614 BACC Author Team (2008) Assessment of climate change for the Baltic Sea basin. Springer, 615 Berlin. 
617 Beitinger TL, Bennett WA, McCauley RW (2000) Temperature tolerances of North

American freshwater fishes exposed to dynamic changes in temperature. Environ Biol Fish 58:237-275.

Belkin IM (2009) Rapid warming of large marine ecosystems. Prog Oceanogr 81:207-213. 622

623 Boehm PD, Fiest DL (1982) Subsurface distribution of petroleum from an offshore well 624 blowout. The Ixtoc-I blowout, Bay of Campeche. Env Tech 16:67-74.

Brette F, Machado B, Cros C, Incardona JP, Scholz NL, Block BA (2014) Crude oil impairs cardiac excitation-contraction coupling in fish. Science 343:772-776.

Casselman MT, Anttila K, Farrell AP (2012) Using maximum heart rate as a rapid screening tool to determine optimum temperature for aerobic scope in Pacific salmon Oncorhynchus spp.. J Fish Biol 80 :358-377.

Chatelier A, McKenzie DJ, Claireaux G (2005) Effects of changes in water salinity upon exercise and cardiac performance in the European seabass (Dicentrarchus labrax). Mar Biol $147: 855-862$

Chen Z, Anttila K, Wu J, Whitney CK, Hinch SG, Farrell AP (2013) Optimum and maximum temperatures of sockeye salmon (Oncorhyncus nerka) populations hatched at different 639 temperatures. Can J Zool 91:265-274. 
641 Claireaux G, Davoodi F (2010) Effect of exposure to petroleum hydrocarbons upon cardio-

642 respiratory function in the common sole (Solea solea). Aquat Toxicol 98:113-119.

644 Claireaux G, Lagardère J-P (1999) Influence of temperature, oxygen and salinity on the 645 metabolism of the European sea bass. J Sea Res 42:157-168.

Davoodi F, Claireaux G (2007) Effects of exposure to petroleum hydrocarbons upon the metabolism of the common sole Solea solea. Mar Pollut Bull 54:928-934.

Drost HE, Carmack EC, Farrell AP (2014) Upper thermal limits of cardiac function for Arctic cod Boreogadus saida, a key food web fish species in the Arctic Ocean. J Fish Biol 84:17811792.

Dussauze M, Camus L, Le Floch S, Pichavant-Rafini K, Geraudie P, Coquillé N, Amérand A, Lemaire P, Theron M (2014) Impact of dispersed fuel oil on cardiac mitochondrial function in polar cod Boreogadus saida. Environ Sci Pollut Res Int 21:13779-13788. 
666 Eliason EJ, Clark TD, Hinch SG, Farrell AP (2013) Cardiorespiratory collapse at high

667 temperature in swimming adult sockeye salmon. Conserv Physiol 1:cot008.

669 Endersen Ø, Sørgård E, Sundet JK, Dalsøren SB, Isaksen ISA, Berglen TF, Gravir G (2003) 670 Emission from international sea transportation and environmental impact. J Geophys Res $671 \quad 108: 4560$.

673 Farrell AP (2009) Environment, antecedents and climate change: lessons from the study of 674 temperature physiology and river migration of salmonids. J Exp Biol 212:3771-3780.

676 Ferreira EO, Anttila K, Farrell AP (2014) Thermal optima and tolerance in the eurythermal 677 goldfish (Carassius auratus): Relationship between whole animal aerobic capacity and 678 maximum heart rate. Physiol Biochem Zool 87:599-611.

680 Forbes VE, Palmqvist A, Bach L (2006) The use and misuse of biomarkers in 681 ecotoxicology. Environ Toxicol Chem 25:272-280.

683 Hicken CE, Linbo TL, Baldwin DH, Willis ML, Myers MS, Holland L, Larsen M, Stekoll

688 Incardona JP, Scholz NL (2016) The influence of heart developmental anatomy on 
Incardona JP, Collier TK, Scholz NL (2004) Defects in cardiac function precede

morphological abnormalities in fish embryos exposed to polycyclic aromatic hydrocarbons. Toxicol Appl Pharmacol 196:191- 205.

Incardona JP, Carls MC, Day HL, Sloan CA, Bolton JL, Collier TK, Scholz NL (2009)

Cardiac arrhythmias is the primary response of embryonic pacific herring (Clupea pallasi) exposed to crude oil during weathering. Environ Sci Technol 43:201-207.

Incardona JP, Linbo TL, Scholz NL (2011) Cardiac toxicity of 5-ring polycyclic aromatic hydrocarbons is differentially dependent on the aryl hydrocarbon receptor 2 isoform during zebrafish development. Toxicol Appl Pharmacol 257:242-249.

Incardona JP, Vines CA, Anulacion BF, Baldwin DH, Day HL, French BL, Labenia JS,

Linbo TL, Myers MS, Olson OP, Sloan CA, Sol S, Griffin FJ, Menard K, Morgan SG, West JE, Collier TK, Ylitalo GM, Cherr GN, Scholz NL (2012) Unexpectedly high mortality in Pacific herring embryos exposed to the 2007 Cosco Busan oil spill in San Francisco Bay. Proc Natl Acad Sci USA 109:E51-E58.

Incardona JP, Gardner LD, Linbo TL, Brown TL, Esbaugh AJ, Mager EM, Stieglitz JD, French BL, Labenia JS, Laetz CA, Tagal M, Sloan CA, Elizur A, Benetti DD, Grosell M, Block BA, Scholz NL (2014) Deepwater Horizon crude oil impacts the developing hearts of large predatory pelagic fish. Proc Natl Acad Sci USA 111:E1510-E1518.

Jobling M (1981) Temperature tolerance and the final preferendum-rapid methods for assessment of optimum growth temperatures. J Fish Biol 19:439-455. 
Johansen JL, Esbaugh AJ (2017) Sustained impairment of respiratory function and swim

performance following acute oil exposure in a coastal marine fish. Aquat Toxicol 187:82-89.

Jung J-H, Hicken CE, Boyd D, Anulacion BF, Carls MG, Shim WJ, Incardona JP (2013)

Geologically distinct crude oils cause a common cardiotoxicity syndrome in developing zebrafish. Chemosphere 91:1146-1155.

Khursigara AJ, Perrichon P, Bautista NM, Burggren WW, Esbaugh AJ (2017) Cardiac

function and survival are affected by crude oil in larval red drum, Sciaenops ocellatus. Sci

Total Environ 579:797-804.

727 Lefrançois C, Claireaux G (2003) Influence of ambient oxygenation and temperature on 728 metabolic scope and scope for heart rate in the common sole Solea solea. Mar Ecol Prog Ser $729 \quad 259: 273-284$.

731 Mager EM, Esbaugh AJ, Stieglitz JD, Hoenig R, Bodinier C, Incardona JP, Scholz NL, 732 Benetti DD, Grosell M (2014) Acute embryonic or juvenile exposure to Deepwater Horizon 733 crude oil impairs the swimming performance of mahi-mahi (Coryphaena hippurus). Environ 734 Sci Technol 48:7053-7061.

735

736 Marshall J, Armour KC, Scott JR, Kostov Y, Hausmann U, Ferreira D, Shepherd TG, Bitz 737 CM (2014) The ocean's role in polar climate change: asymmetric Arctic and Antarctic 738 responses to greenhouse gas and ozone forcing. Phil Trans R Soc A 372:20130040. 
Mauduit F, Domenici P, Farrell AP, Lacroix C, Le Floch S, Lemaire P, Nicolas-Kopec A,

Whittington M, Zambonino-Infante JL, Claireaux G (2016) Assessing chronic fish health: An application to a case of an acute exposure to chemically treated crude oil. Aquat Toxicol 178:197-208.

745 Mercier C, Aubin J, Lefrançois C, Claireaux G (2000) Cardiac disorders in farmed adult 746 brown trout (Salmo trutta). J Fish Dis 60:117-137.

748 Meski L, Kaitaranta J (2014) HELCOM Annual report on shipping accidents in the Baltic

749 Sea in 2013. HELCOM - Baltic Marine Environment Protection Commission, Helsinki.

Milinkovitch T, Godefroy J, Théron M, Thomas-Guyon H (2011) Toxicity of dispersant application: Biomarkers responses in gills of juvenile golden grey mullet (Liza aurata).

Environ Poll 159 :2921-2928.

Milinkovitch T, Lucas J, Le Floch S, Thomas-Guyon H, Lefrançois C (2012) Effects of dispersed crude oil exposure upon the aerobic metabolic scope in juvenile golden grey mullet (Liza aurata). Mar Pollut Bull 64:865-871.

Milinkovitch T, Thomas-Guyon H, Lefrançois C, Imbert N (2013) Dispersant use as a response to oil spills: toxicological effects on fish cardiac performance. Fish Physiol Biochem 39:257-262. 
Muñoz NJ, Anttila K, Chen Z, Heath JW, Farrell AP, Neff BD (2014) Indirect genetic effects

underlie oxygen-limited thermal tolerance within a coastal population of Chinook salmon.

Proc R Soc B 281:20141082.

Nelson D, Heuer RM, Cox GK, Stieglitz JD, Hoenig R, Mager EM, Benetti DD, Grosell M, Crossley II DA (2016) Effects of crude oil on in situ cardiac function in young adult mahimahi (Coryphaena hippurus). Aquat Toxicol 180:274-281.

Nordvik AB (1995) The technology windows-of-opportunity for marine oil spill response as 772 related to oil weathering and operations. Spill Sci Technol Bull 2:17-46.

Pörtner HO (2010) Oxygen- and capacity-limitation of thermal tolerance: a matrix for integrating climate-related stressor effects in marine ecosystems. J Exp Biol 213:881-893.

Priede IG (1974) Effect of swimming activity and section of vagus nerve on heart rate in rainbow trout. J Exp Biol 60:305-319.

Ramachandran SD, Hodson PV, Khan CW, Lee K (2004) Oil dispersant increases PAH uptake by fish exposed to crude oil. Ecotoxicol Environ Saf 59:300-308. 
Sadauskas-Henrique H, Braz-Mota S, Duarte RM, Almeida-Val VMF (2016) Influence of the natural Rio Negro water on the toxicological effects of a crude oil and its chemical dispersion to the Amazonian fish Colossoma macropomum. Environ Sci Pollut Res 23: 19764-19775.

Sandrini-Neto L, Geraudie P, Santana M, Camus L (2016) Effects of dispersed oil exposure on biomarker responses and growth in juvenile wolfish Anarhichas denticulatus. Environ Sci Pollut Res 23:21441-21450.

794 Sanni S, Björkblom C, Jonsson H, Godal BF, Liewenborg B, Lyng E, Pampanin DM (2016)

795 I: Biomarker quantification in fish exposed to crude oil as input to species sensitivity

796 distributions and threshold values for environmental monitoring. Mar Environ Res 125:10-24.

798 Steinhausen MF, Sandblom E, Eliason EJ, Verhille C, Farrell AP (2008) The effect of acute 799 temperature increases on the cardiorespiratory performance of resting and swimming sockeye 800 salmon (Oncorhynchus nerka). J Exp Biol 211:3915-3926.

807 Sørhus E, Incardona JP, Karlsen Ø, Linbo T, Sørensen L, Nordtug T, van der Meeren T, 808 Thorsen A, Thorbjørnsen M, Jentoft S, Edvardsen RB, Meier S (2016) Crude oil exposures 809 reveal roles for intracellular calcium cycling in haddock craniofacial and cardiac 810 development. Sci Rep 6:31058. 
2812 Teng H, Branstator G, Meehl GA, Washington WM (2016) Projected intensification of

513 subseasonal temperature variability and heat waves in the Great Plains. Geophys Res

814 Lett 43:2165-2173.

815

11 
a

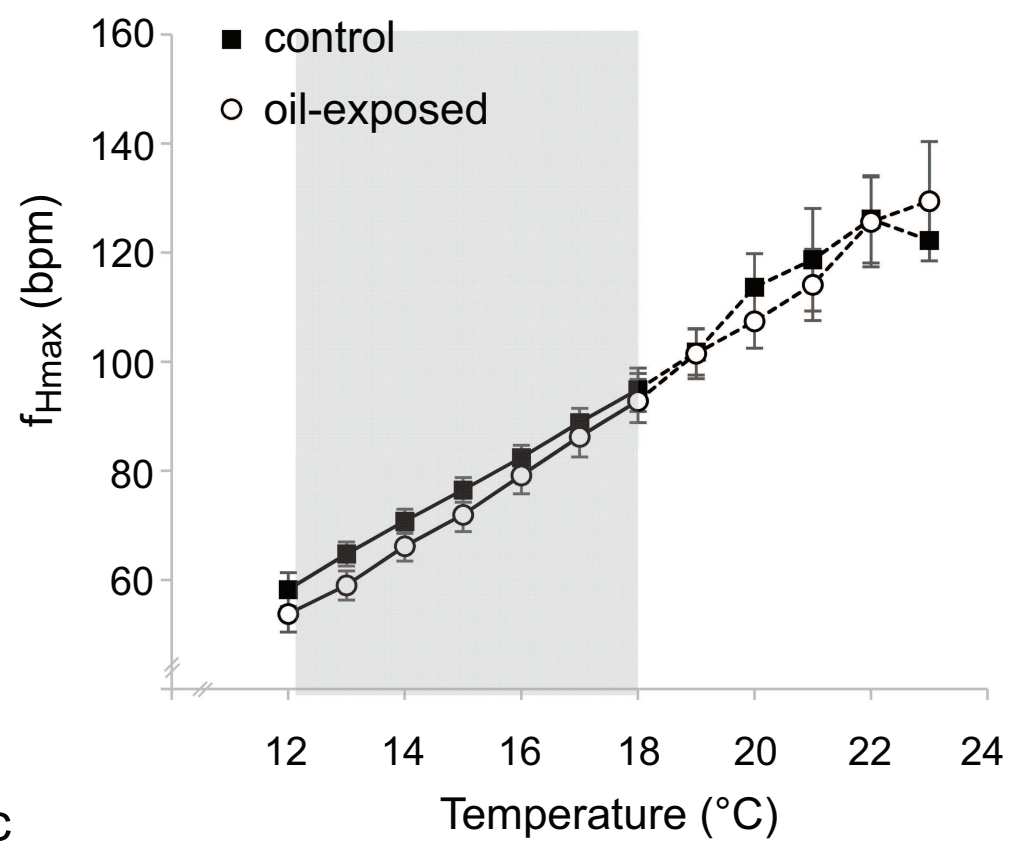

C

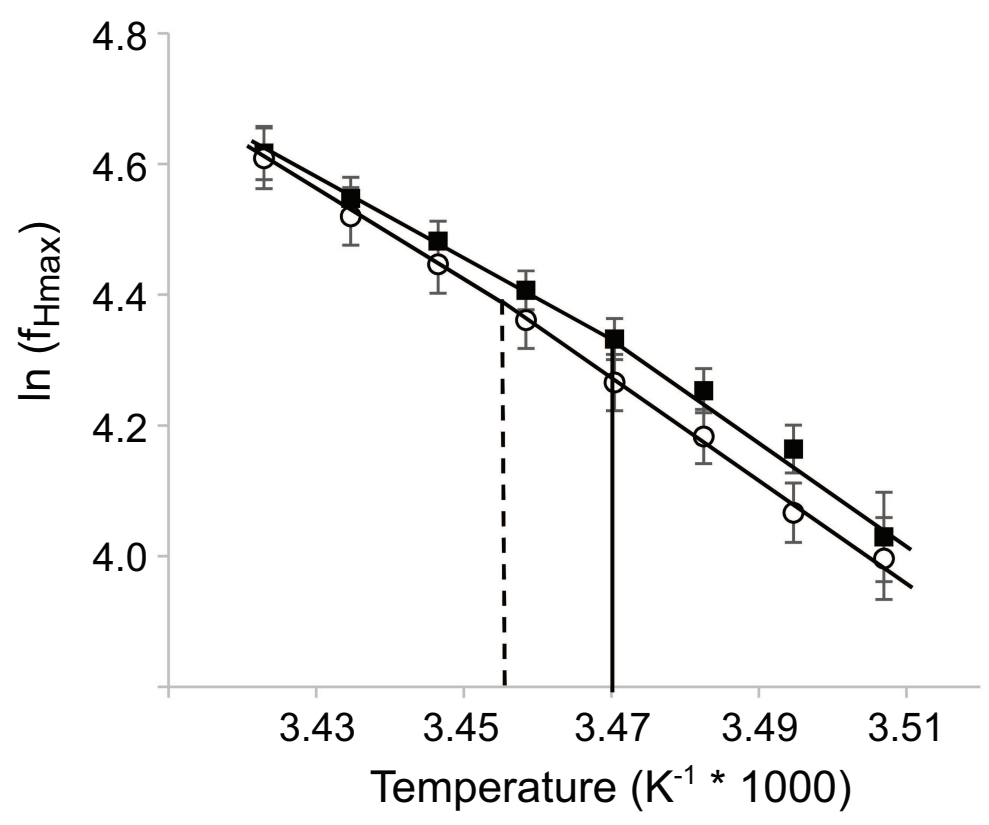

$\begin{array}{llllllll}19 & 18 & 17 & 16 & 15 & 14 & 13 & 12\end{array}$ Temperature $\left({ }^{\circ} \mathrm{C}\right)$ b

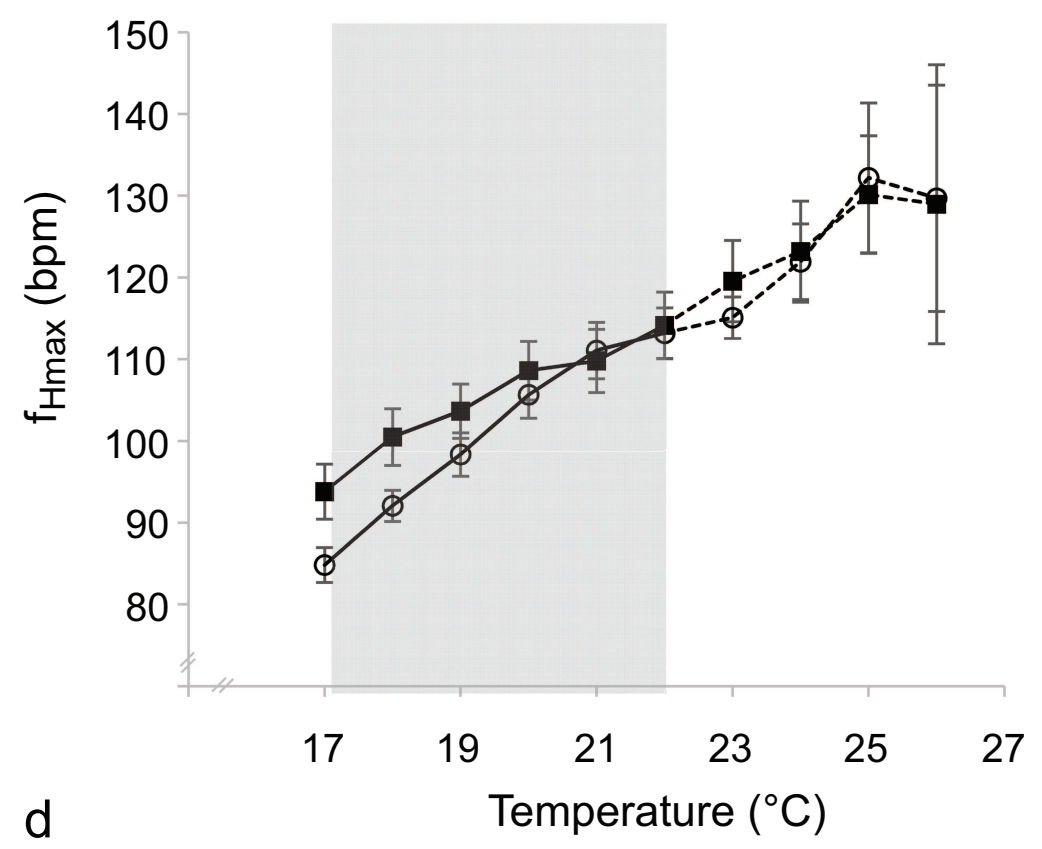

4.9

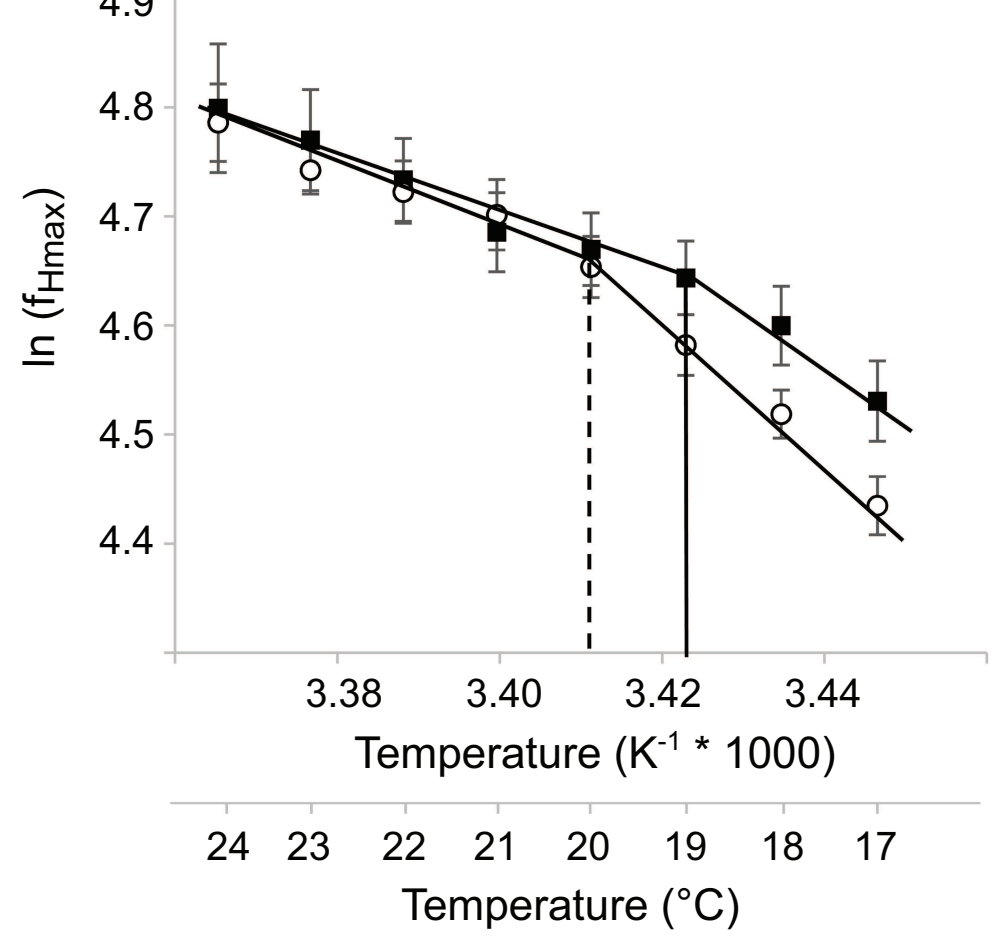


a

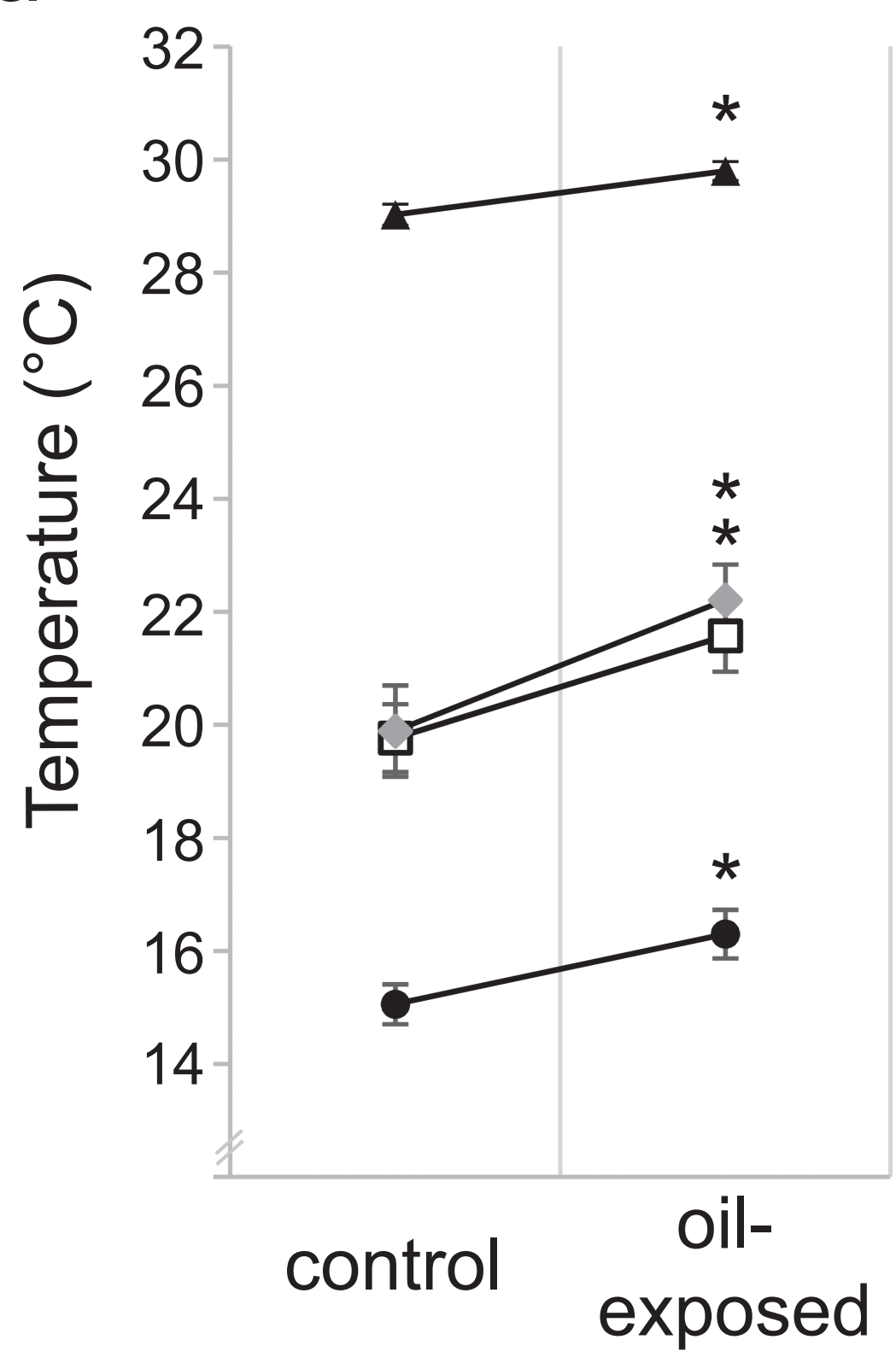

b

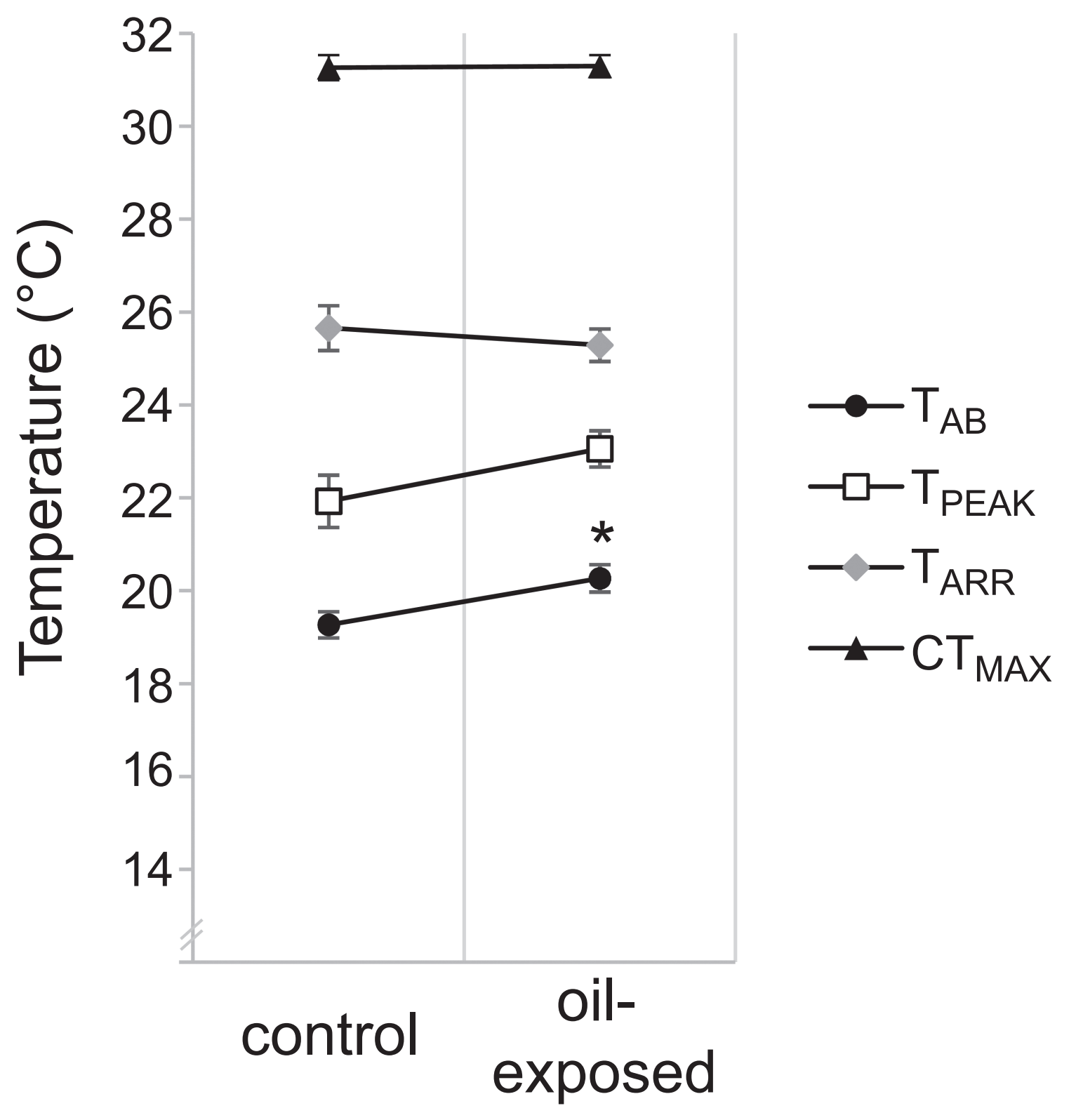


Click here to access/download Supplementary Material Supplementary methods and table.pdf 